\title{
A PORTABLE APPARATUS FOR PHOTOGRAPHING CURVES OF TWO VARIABLE CURRENTS SIMULTANEOUSLY.
}

By H. J. Hotchistss.

$\mathrm{T}^{\mathrm{H}}$

$\mathrm{HE}$ apparatus was presented at the Buffalo meeting of the American Association for the Advancement of Science in I896, at which time a brief abstract was given in the Electrical World, September 26th. A more complete description has been delayed until a few details of construction were more fully developed.

The non-portable single-curve apparatus from which the present form was developed was described in the Physical Review, July, I $895^{1}$ The purpose of this article is to describe the present form of the apparatus and give a few curves without taking up any special experiments performed with it.

The aim in designing was to provide a portable instrument which will give continuous simultaneous records of two variable currents or potentials so as to show their corresponding values at any instant. The variations whether cyclic or noncyclic are recorded as fast as they occur, the special province of the apparatus being in experiments dealing with rapid noncyclic variations. The corresponding values of any number of cyclic curves may be obtained by taking two, then one of these with a third, and so on.

The principal parts are two quick acting galvanometers of the Deprez type with minute moving parts supported by a quartz fiber in the strong field of a permanent magnet. These are mounted one above the other in one end of a case about $6 \times 61 / 2 \times 18$ inches, shown in Fig. I. In the other end of the case is a revolving drum

${ }^{\wedge}$ Experiments in which the single-curve apparatus was used are described by F. E. Millis in the Physical Review, March, 1896, p. 35I ; and September, I896, p. I28; and others by F. J. A. McKittrick in Trans. A. I. E. E., Vol. I3, May 20, 1896. Some experiments and considerations leading to the present form were discussed in a thesis by the writer in $\mathbf{I} 896$. 
carrying a photographic film. The arrangement of parts inside may be seen by referring to Fig. 6 .

Sun light or arc light is directed through two narrow slits in the side of the case upon the very small mirrors of the moving parts, which we will call the needles. From the mirrors the two beams are reflected upon a horizontal slit in the drum-box. As the needles are deflected by the current in the galvanometer coils the spots of light move along the slit and trace the curves on the film which moves rapidly at right angles to the slit. The drum-box may be removed and replaced by a slideway for using plates, as seen in Fig. 3, in which the drum-box is used simply as a support or one end of the case.

The needle is a very small piece of soft iron mounted on one side of a quartz fiber with a mirror, about one-third as large as the iron, on the other side. The fiber is supported vertically in the instrument. A medium size for the iron is: $1 \mathrm{~mm}$. wide, $1.9 \mathrm{~mm}$. long with rounded ends, and $.06 \mathrm{~mm}$. thick. The long dimension is vertical along the fiber so as to make the moment of inertia small and the frequency of natural vibration high.

The fiber is supported at both ends on a quartz bow or rod about I $\mathrm{mm}$. in diameter and I $\mathrm{cm}$., or less, in length. The bow is then mounted in a groove, cut lengthwise in the side of a $\frac{5}{32}$-inch rod, about $4.5 \mathrm{~cm}$. long, so that the fiber lies in the axis of the rod as shown full size in Fig. 5.

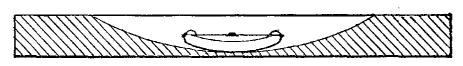

Fig. 5.

The quartz fibers are mounted on quartz in order to avoid the effects of temperature changes as far as possible. The increase of rigidity $^{1}$ with rise of temperature, being only about .o I of one per cent. per degree centigrade, is negligible.

Needles have been made having a natural frequency of over 8,500 double vibrations per second in the comparatively weak field of a permanent magnet weighing about I.3 kilos. With a strong

is. J. Barnett, Physical Review, Feb. 1898, p.ir4. R. Threlfall, on Laboratory Arts, p. 218. 
field and a stiff fiber a frequency of 10,000 double vibrations per second could be obtained. One needle was broken before a reliable test was made, but an approximate measurement gave a frequency of about 9,300.

The frequencies of the needles used in taking the curves shown in Figs. 7-9 and $I 1-13$ are about 5,300 for the voltmeter and 4,200 for the ammeter. The measurements of frequency were made by deflecting the needle by a direct current, then while the plate is before the slit and moving at a speed of about $382 \mathrm{cms}$. per second the electro-motive force impressed upon the coils is instantly removed by short-circuiting them by means of an automatic mercury switch, leaving the needle free to vibrate due to its inertia. The damping and moment of inertia are small, allowing the needle to respond promptly to variations of current. If very abrupt changes of current cause the needle to vibrate, the mean line gives the true value. Although the appearance of such curves is bad, they are not rendered useless by the vibration.
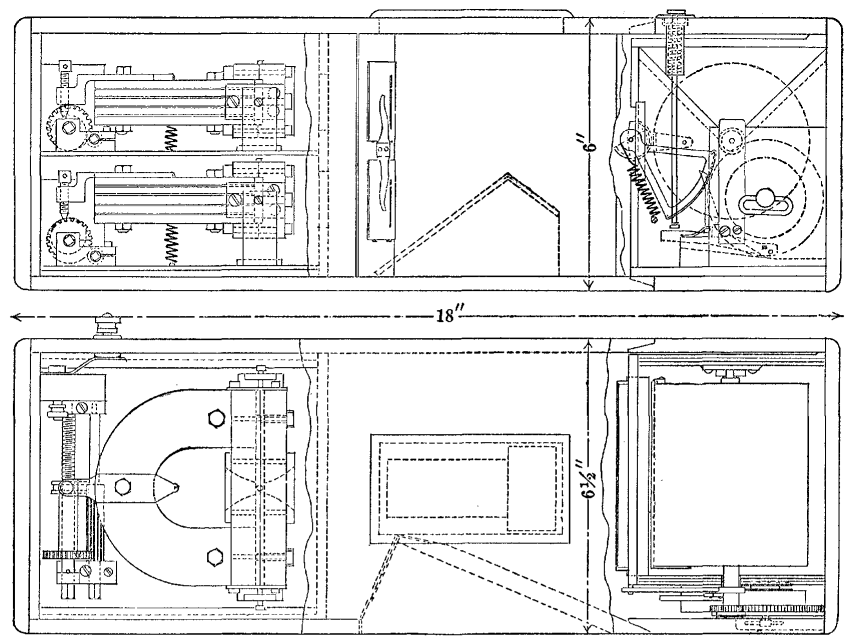

Fig. 6.

The needles are interchangeable so that those of different frequencies and degrees of sensitiveness may be used for different purposes. The galvanometer coils are likewise interchangeable and may also be connected either in series or parallel. In the galvanometers 
shown in Fig. 2, one has about 35 turns of number 16 wire in each coil and the other 600 turns of number 30 wire B. \& S. gauge, the outer diameter of the coils being $2.5 \mathrm{cms}$. and the resistances .07 and $17.4 \mathrm{ohms}$ respectively, when each pair is connected in series.

The parts of the galvanometers may be seen in Figs. 2 and 6. The needle rod, coils, and soft-iron pole pieces ${ }^{1}$ are held in position between the magnet poles by a two-part hard rubber block which in turn is supported on a base so as to move about a horizontal and a vertical axis through the needle for the purpose of adjusting without displacing the needle. The rear of the magnet is carried sidewise by a screw and moved vertically by a cam, both being operated by a key through a small opening in the side of the case. The spots of light are thus properly adjusted on the slit of the drum box or slideway. For convenience in adjusting, a block on which are two inclined mirrors is placed directly below the opening in the top of the case. In one the galvanometer fronts are in view, and in the other are seen the lines of light on the slits.

When the adjustments are made the galvanometer circuits are closed, and, if films are used, the photograph is taken by pressing the push button seen on the top of the case in Fig. I. This releases the driving mechanism which brings the drum up to speed and then automatically operates the cylindrical shutter which exposes the film for a single revolution of the drum, beginning and ending the record at the latch that holds the ends of the film. How this is done may be better understood by noting the interior arrangement in the horizontal and vertical projections in Fig. 6, and also Fig. 2, in which it is taken apart showing the inner drum case with its lid removed ready to take out the drum for putting on the film.

A strong spring, wound up by the key shown, actuates a gear wheel which engages a pinion on the drum shaft. Pressing the push button moves a lever and releases the gear wheel for one revolution at the end of which it stops so that the pinion is free to turn in a gap where three or four teeth are cut away and the drum con-

${ }^{1}$ The pole pieces are $2.5 \mathrm{~cm}$. wide and $.48 \mathrm{~cm}$. thick, with the ends next to the needle rod tapered down to about $3 \mathrm{~mm}$. wide and $\mathrm{I} \mathrm{mm}$. thick. These tapered points are not shown in Fig. 6, owing to the small scale. 
[Vol. VIII.

tinue the high speed attained. Just as the gear stops it releases an arc-shaped arm from the cylindrical shutter which then makes a rolling contact with a small roughened wheel on the drum shaft. The parts are so proportioned that the opening in the shutter uncovers the slit during one revolution of the drum; the arc subtended by the opening in the cylinder being the same as that over which the arm is carried by one revolution of the roughened wheel.

If the slideway shown in Fig. 3 is used instead of the drum, it is operated by giving the thumb nut at the end of the spring a onefourth turn either way, thus releasing the spring which withdraws a pin on which the plateholder rests. The plate is then shot downward by a strong spring acting on the pin in the slot at the top. The spring ceases to act upon the plate just before it comes to the slit. A vent at the bottom for the escape of the air can be adjusted so as to maintain the speed of the plate very nearly uniform while passing the slit; probably within one-tenth of one per cent. A latch keeps the plate from bounding back after striking the felt pad at the bottom.

Since the rays from the two needles pass through the slit at an angle it is necessary to have the plate pass very close to the slit to get the true phase relations of the two curves. To do this the plate holder is made as shown at the top of Fig. 2. It takes an eight-inch plate of any width up to five inches, and brings it within $.8 \mathrm{~mm}$. of the slit.

In Figs. 7-I 5 are shown a few curves representing current and electro-motive force from alternators having different wave forms, and different kinds of external circuits containing resistance, selfinduction or capacity. They were taken on plates 2.5 by 8 inches except Fig. I 5 for which a full-sized 5 by 8 plate was used instead of a half plate. The curves are reproduced full size, but only a part from each plate is shown.

Figs. 7 and 8 were obtained for the purpose of testing the accuracy with which the phase relations of $E$ and $I$ are represented. The connections to one galvanometer were reversed so as to reverse the deflection and get a sharply defined crossing of the lines instead of superposition to indicate no lag when incandescent lamps are used. The intersections are found to lie in the same straight 
Plate I.

Physical Revinw, XliI.

(To face page 156 .)

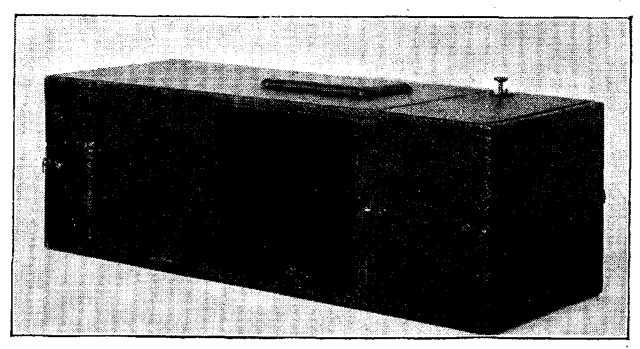

Fig. 1.

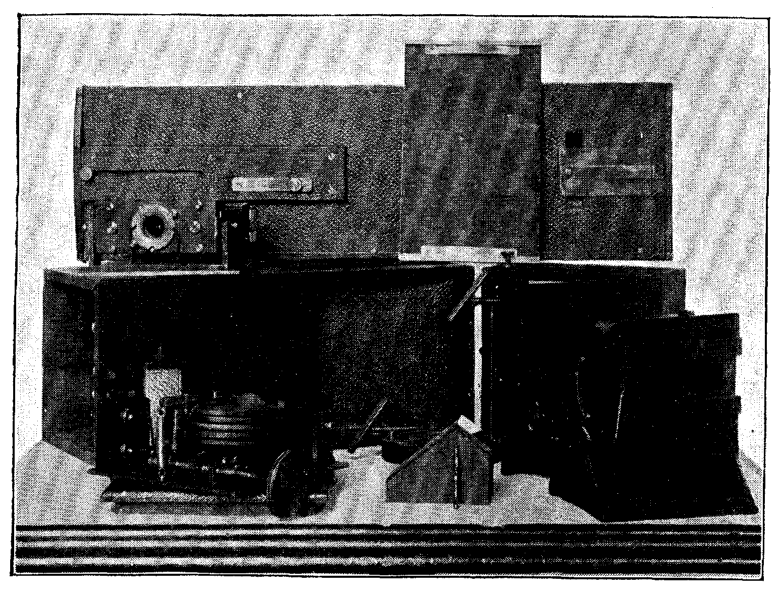

Fig. 2.

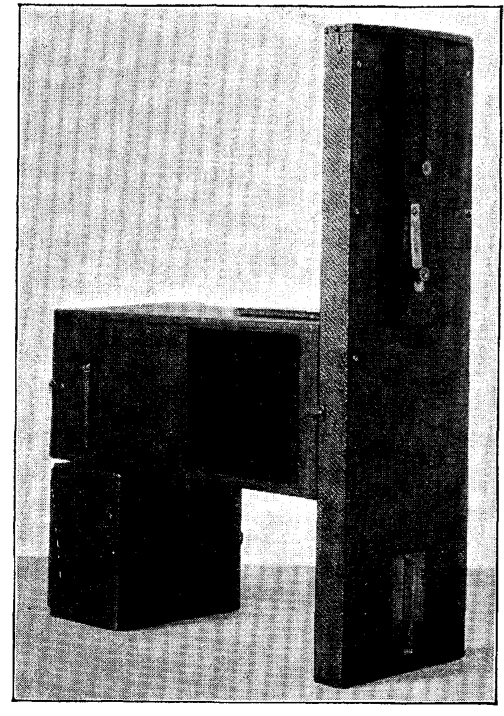

Fig. 3. HOTCHKISS: Alternating Current Curves.

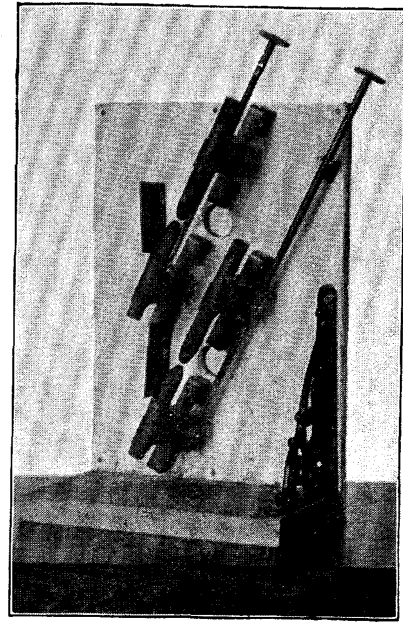

Fig. 4. 
line. This indicates that the phase relations shown by the instrument are reliable.

At first the voltmeter was placed below the ammeter, thus displacing the $E$ curve relative to the other, about $.2 \mathrm{~mm}$. in the direction of lag. This error was further increased slightly by the selfinduction of the fine wire coils of the voltmeter. Fig. 9 was taken with the voltmeter below. The slight lag of the $E$ curve is probably due to these errors. By placing the voltmeter above the ammeter, as used later for Figs. 7 and 8 , these errors tend to compensate and all of the tests made indicate that the compensation is quite exact.

The curves in Fig. 8 have their lines of symmetry slightly separated, due to an accidental displacement of the zero of one galvanometer just before the exposure. The self induction in the armature of the alternator makes the notches in the current curve of less depth than those in the other. The slightest perceptible variations of the form or shading of any one wave from that of the others of a single revolution have been found to be exactly reproduced in the corresponding wave of the next revolution.

The laboratory transformers, used for Figs. 7, 9 and 13 are operated from a 2200-volt General Electric Co. alternator running at a frequency between $\mathrm{I} 28$ and I 30 cycles per second. The following tables gives for the various generators used some approximate values for frequency and virtual current and electro-motive force.

TABLE I.

\begin{tabular}{|c|c|c|c|c|}
\hline Fig. & Generator. & $I$ & $E$ & Frequency. \\
\hline 7 & General Electric Co. Alt. and $\operatorname{Tr} . .$. & - & 55 & 130 \\
\hline 8 & Westinghouse Pony Alt. $\quad \ldots .$. & - & - & 135 \\
\hline 9 & General Electric Co. Alt. and Tr. . . . . & 10.4 & 96 & 130 \\
\hline 10 & Brush Alt. and Tr. . . . . . . . & $0.33^{3}$ & 110 & 115 \\
\hline 11 & Special Alt. ${ }^{1} \ldots \ldots \ldots$ & 13.2 & 27 & 65 \\
\hline 12 & " $\quad$ " $\quad . . . \quad \ldots$. & 12.5 & 29 & 60 \\
\hline 13 & General Electric Co. Alt. and Tr. . . . . & 10.0 & 106 & 130 \\
\hline 14 & Sprague Alt. ${ }^{2} \ldots \ldots \ldots$ & - & 17 & 17 \\
\hline 15 & " " & - & 30 & 17 \\
\hline
\end{tabular}

1 Designed and constructed by students in Sibley College, Cornell University.

${ }^{2}$ A Io-H. P. Sprague D. C. motor changed to a 3-phase generator by putting three rings on the commutator. A single phase was used.

${ }^{3}$ Computed. 
The capacity for Fig. $10^{1}$ was about 4.2 microfarads, being three Stanley condensers in parallel. The resistance in the voltmeter circuit was about I $20 \mathrm{ohms}$.

In Fig. I 2 the ripples on the $E$ curve, due to the grooved armature core, are entirely removed from the current curve by the solenoid in the circuit. In Fig. I 3 also the forms of the curves differ very much due to the solenoid.

The electrodes of the electrolytic cell used for Figs. I4 and I 5 consisted of an arc light carbon with a helix of No. Io aluminium wire around it and about $\mathrm{I} \mathrm{cm}$. away. These were placed in a saturated solution of alum with a little sulphuric acid added. The zero line was traced by a fine wire placed across the slit in the slideway. The shadow of the wire made a break in the curve every time the beam of light crossed it.

The cell allows a comparatively large current to flow from carbon to aluminium, but offers great opposition to the flow of current from aluminium to carbon in the cell. The $E$ curve shows the difference of potential around both the cell and the current galvanometer; hence the fall of potential in the latter must be subtracted from the ordinates of the $E$ curve to give the difference of potential impressed at the terminals of the cell. One centimeter deflection represents .555 ampère for the $I$ curve, and 10.82 volts for the $E$ curve. The fall of potential in the current galvanometer is 9.35 volts for each centimeter of ordinate of the current curve. Fine wire coils of high resistance were used for both galvanometers for Figs. 10, I4 and I 5 .

From the data given the values in the following table were obtained for the parts of the curves above and below the zero lines in Figs. I4 and I 5 .

The lack of symmetry of the $E$ curve is due to the drop in the resistance (about I ohm) between the generator and the apparatus.

The curves may be made heavy, or light and narrow. To obtain narrow lines with sunlight it is directed upon the needle mirrors from reflectors, about I mm. wide, placed about I meter from the

1 For correct phase relations turn the right end to the left, then imagine one curve rotated $\mathbf{I} 80$ degrees about its axis of symmetry. One pair of galvanometer terminals were reversed by mistake, and no later opportunity was found to get a correct one as the Brush generator was used for only a short time during some repairs. 
needles. The slit in front of the plate is about $.5 \mathrm{~mm}$. wide. The line of light across the slit may be made even narrower than that. No lenses are used. The small mirror gives an image in much the same way as a pinhole camera.

TABLE II.

\begin{tabular}{c|c|c|c|c}
\hline & \multicolumn{2}{|c|}{ Fig. x4. } & \multicolumn{2}{c}{ Fig. I5. } \\
\cline { 2 - 5 } & Above. & Below. & Above. & Below. \\
\hline Maximum volts for $E$ curve & 24. & 23. & 42.5 & 40.7 \\
" ampères for $I$ curve & .07 & .98 & .39 & 1.76 \\
" volts on cell & 23.5 & 6.6 & 36. & 11. \\
Volts for zero current & +23. & -4. & +30. & -4. \\
Direction of current in cell & Al. to Carb. & Carb. to Al. & Al. to C. & C. to Al. \\
\hline
\end{tabular}

When using arc lights no reflectors need be used, but narrow slits should be placed close to the arcs. One arc lamp and one reflector may be used instead of two arcs. The pair of hand-fed arcs shown in Fig. 4, have been found to be very convenient, being light and easily adjusted. Turning the screw changes the length of the arc. Pulling and pushing the screw moves the arc up and down on the slides. The bottom of the metal slit is bent around the lower carbon. The maximum intensity of light is nearly horizontal on the side towards the slit. The round windows in the upright are covered with colored glass for viewing the arc while adjusting it. The upright is covered with asbestos board. The terminals on the back are connected to the metal slides. The screws are insulated from the circuits.

That the deflection is very nearly proportional to current is evident from the calibration curves in Fig. I6. The ordinates of the ammeter curve are plotted from the top downward so as to separate the curves. The slight excess of deflection for large currents can probably be easily eliminated by changing the form of the soft-iron pole tips. An earlier form with longer air gap and an electro-magnet gave exact proportionality.

The instrument shown in Figs. I-3 is the only one that has been made. ${ }^{1}$ It was constructed (except the needles and slideway) by Mr. F. C. Fowler, the instrument maker to the Department of

1 They are to be manufactured and sold by Elmer G. Willyoung \& Co., Philadelphia, Pa. 
Physics. The ingeniously arranged driving mechanism and shutter for the drum-box were devised by him to replace the one designed by the writer and is a great improvement.

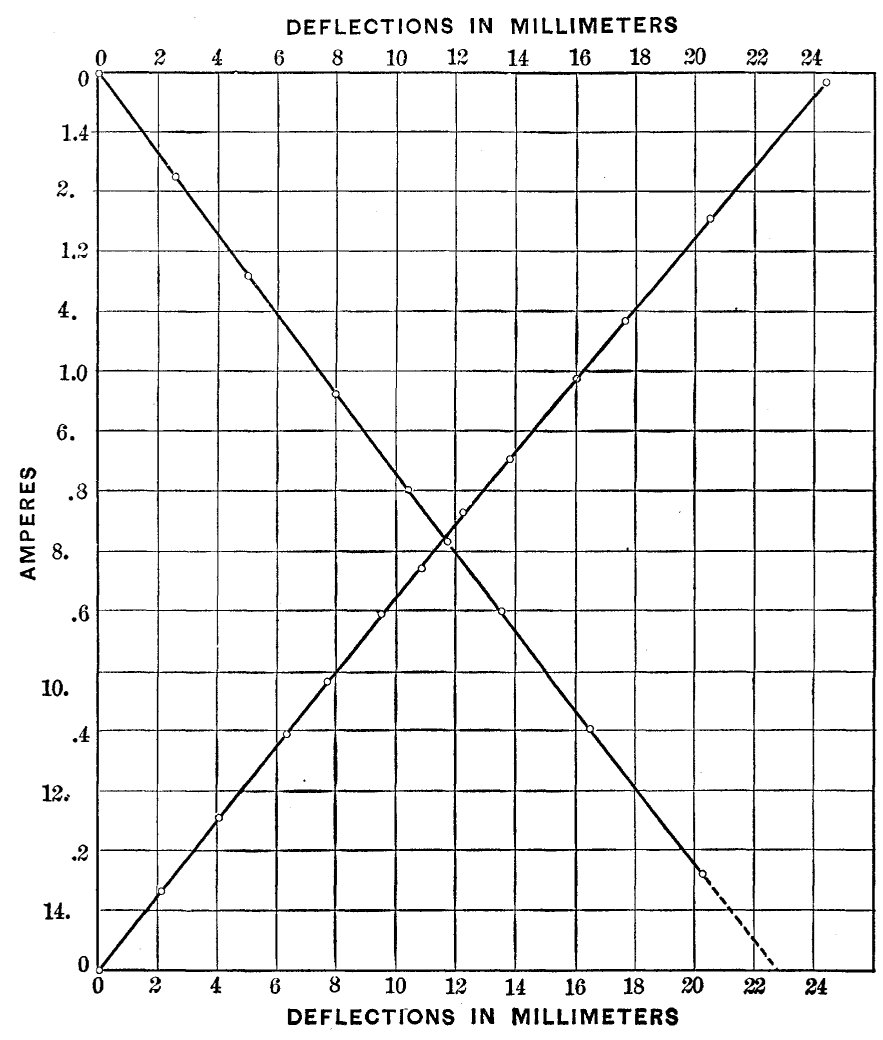

Fig, 16.

The original design included a vibrator of known frequency with a small mirror attached for tracing either a curve on the plate as a time record, or a straight datum line with the mirror at rest. Another part, not yet completed, is an automatic switch for opening or closing the circuit or short-circuiting any part of it while the plate is moving past the slit. It is intended also to have an electromagnet that will be interchangeable with the permanent magnets for experiments in which a very strong field is desired. Apparatus of different forms for special uses has been devised and is in progress.

Physical Laboratury of Cornell University. 

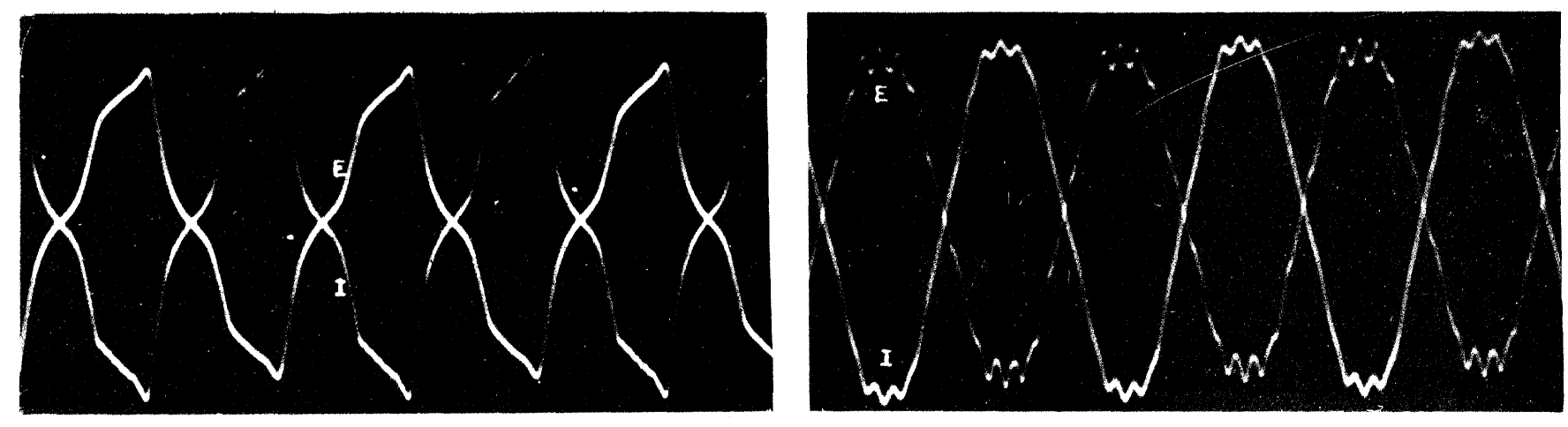

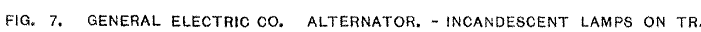
one galvanometer reVERSED to separate cuRves.

FIG. 8. WESTINGHOUSE PONY ALTERNATOR. - INCANDESGENT LAMPS
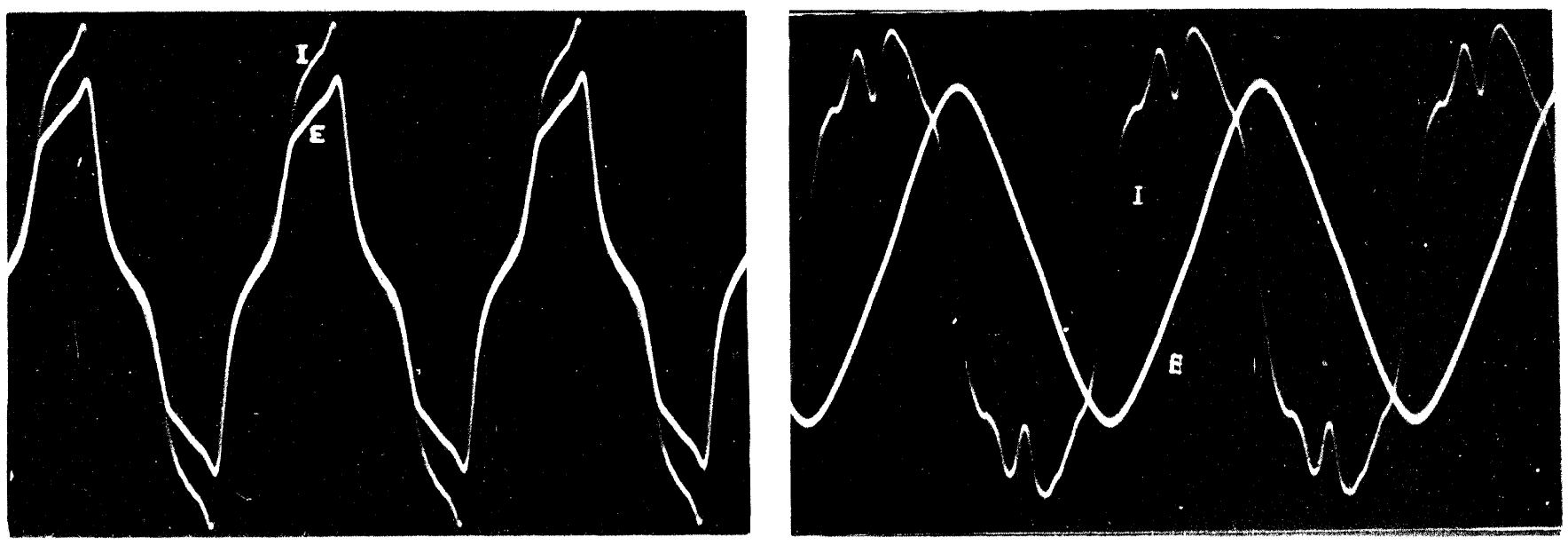

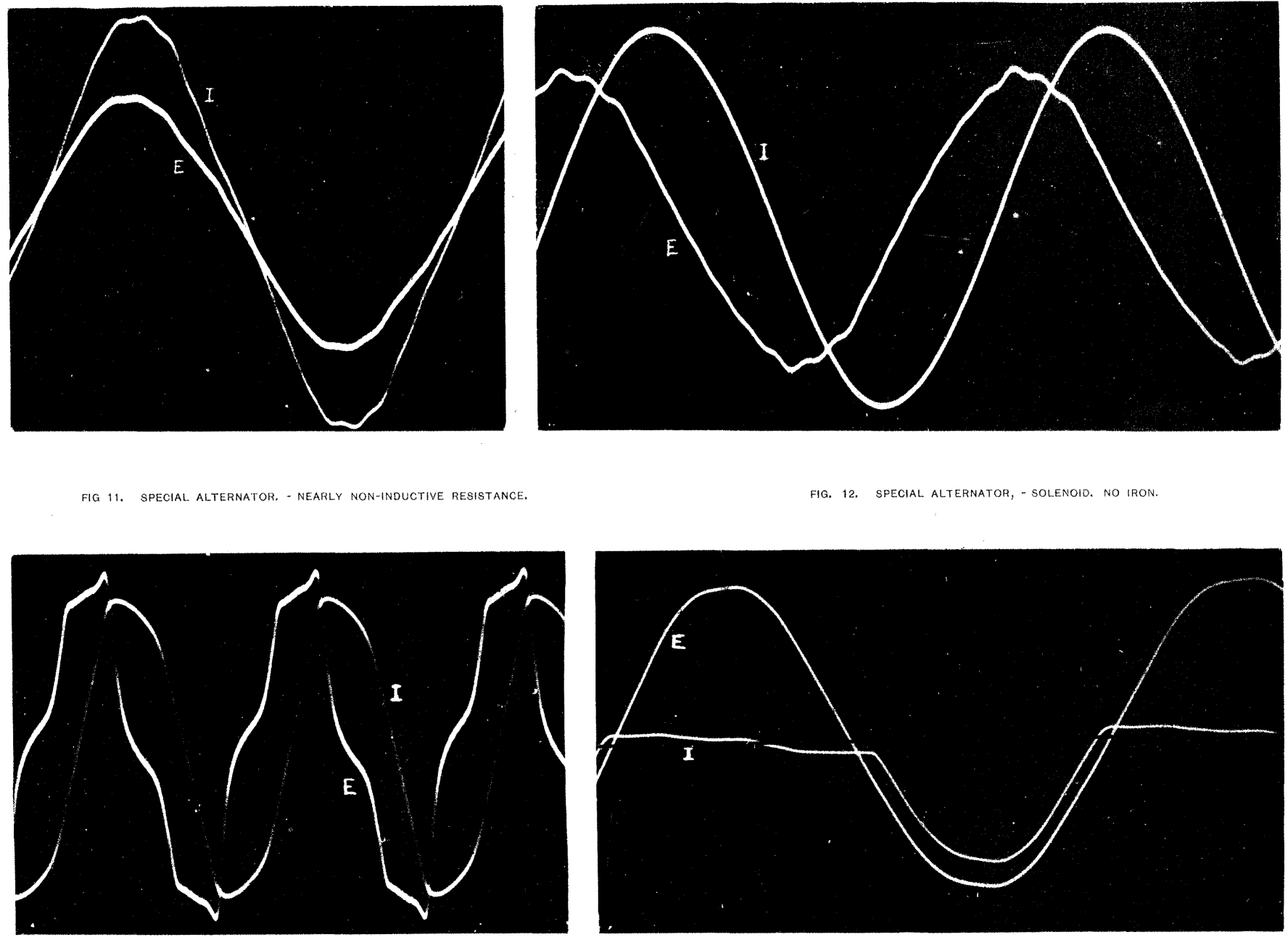
PHYSICAL REVIEW XLII,

PLATE II.
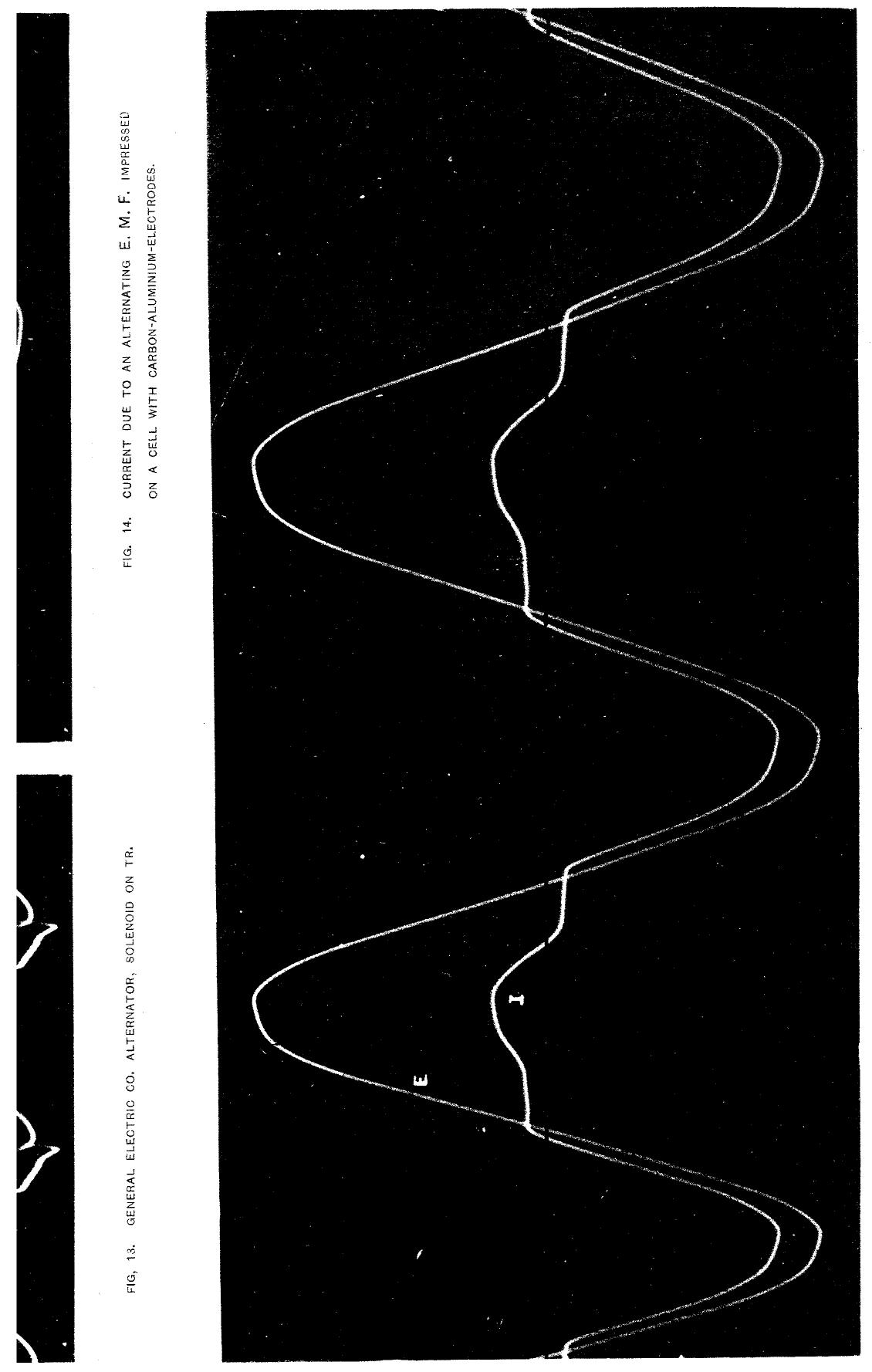

To face page 160 .

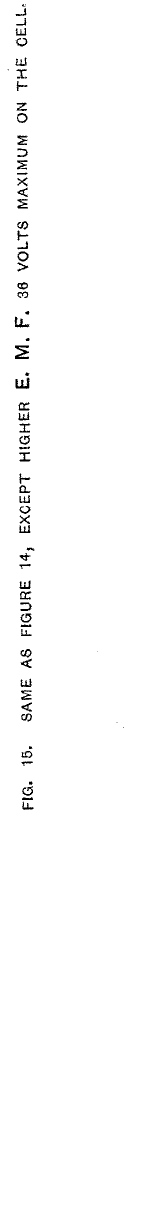




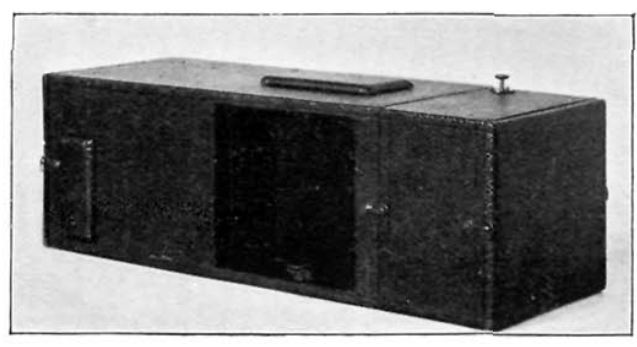

Fig. 1. 


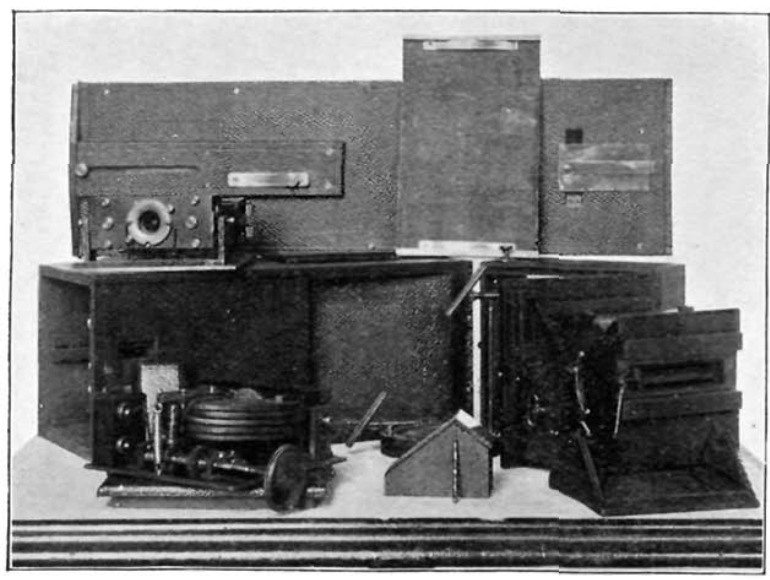

Fig. 2. 


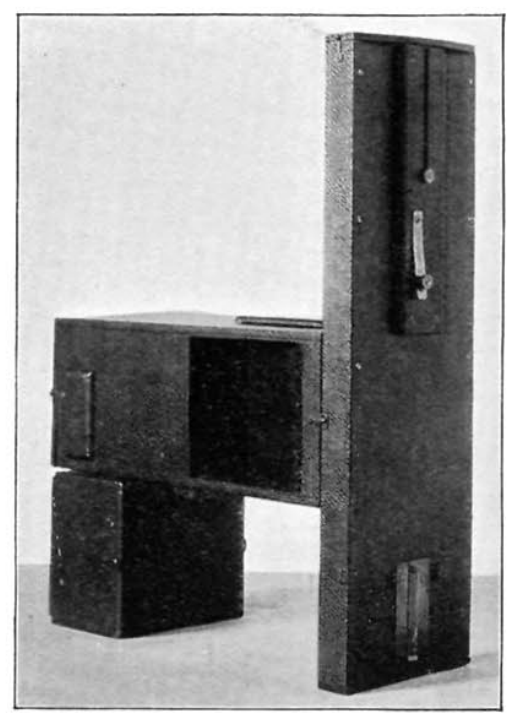

Fig. 3. 


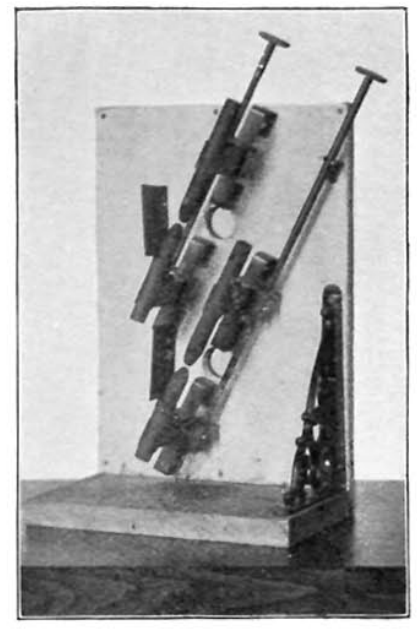

Fig. 4. 

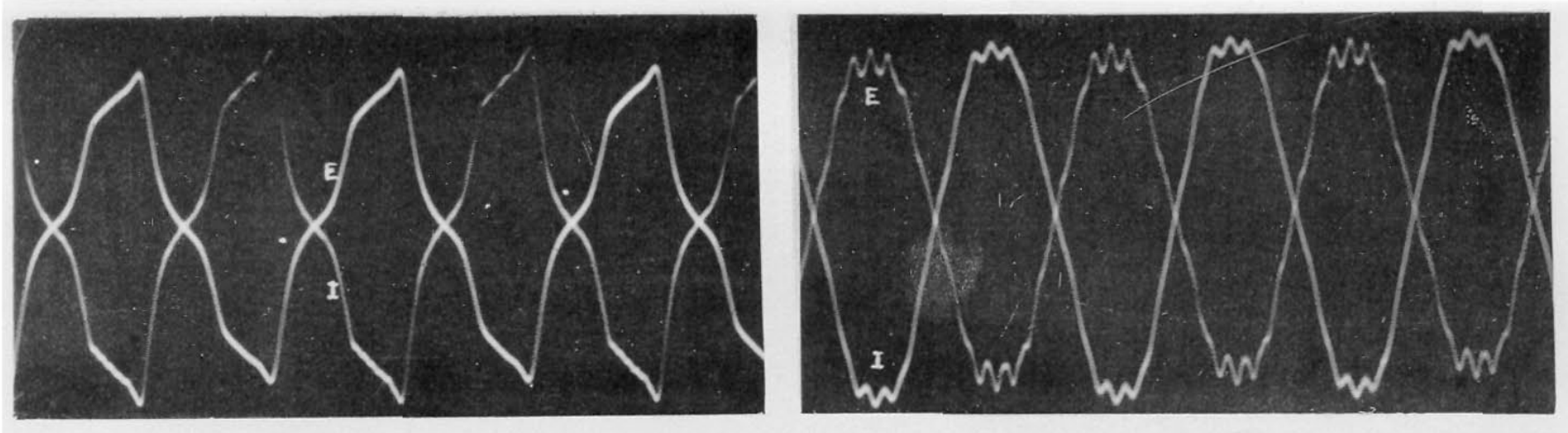

FiG. 7. GENERAL ELECTRIC CO. ALTERNATOR. - INCANDESCENT LAMPS ON TR.

ONE GALVANOMETER REVERSEO TO SEPARATE CURVES.

FIG. 8. WESTINGHOUSE PONY ALTERNATOR. - INCANDESCENT LAMPB.
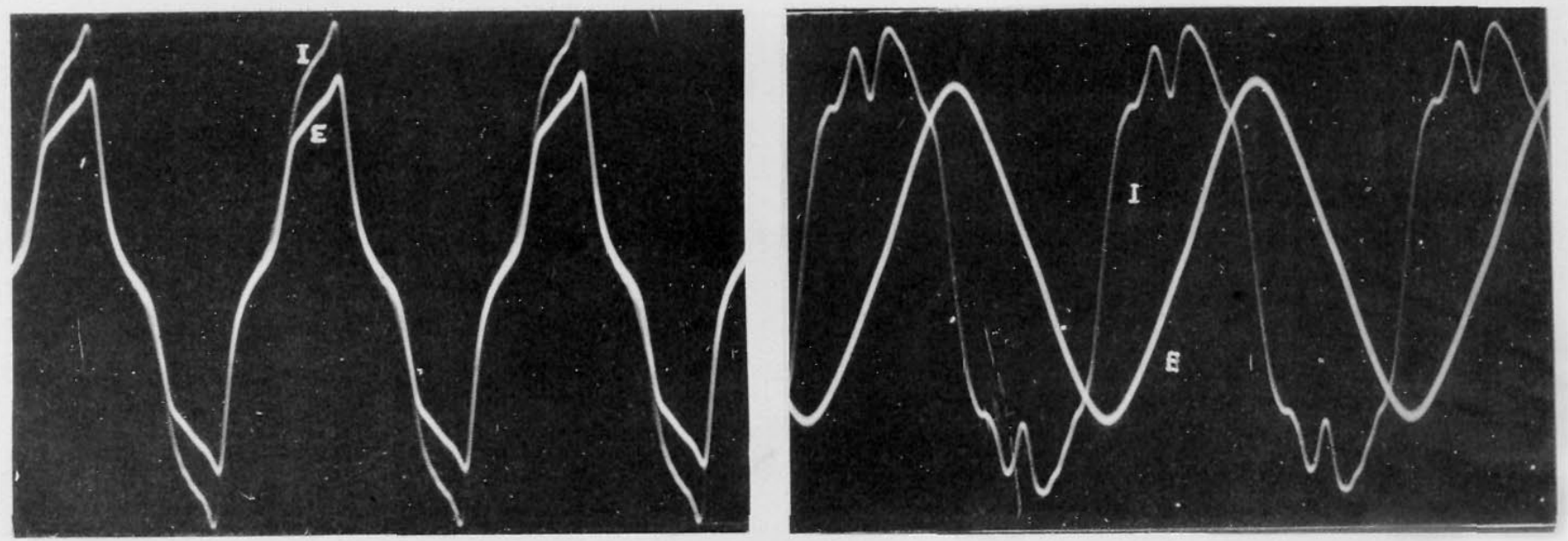

FIG. 9. GeNERAL ELECTRIC CO. ALTERNATOR. NON-INDUCTIVE RESISTANCE ON TR.
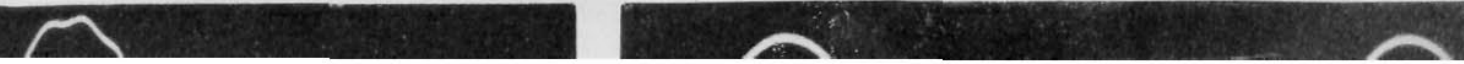


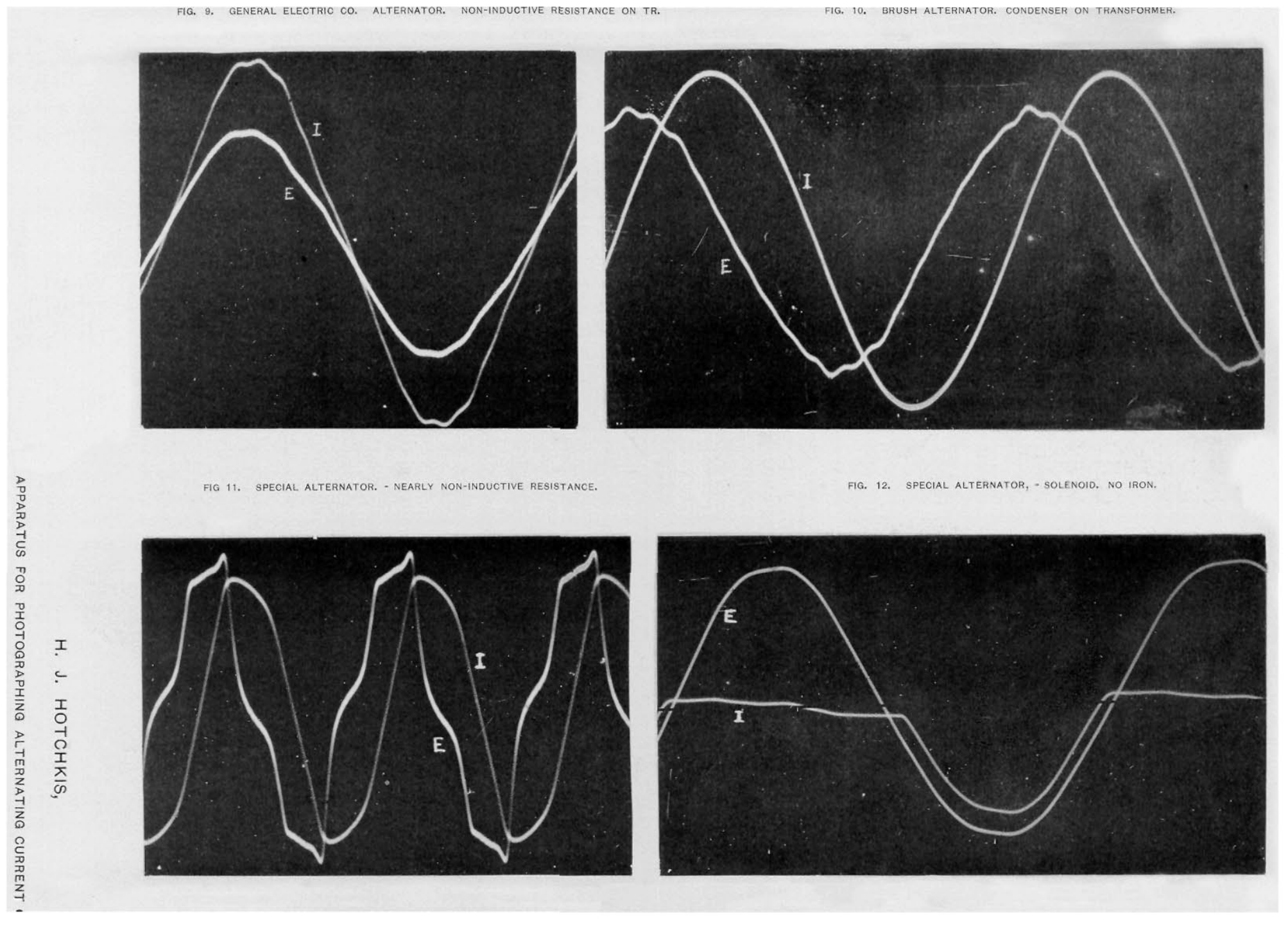


PHYSICAL REVIEW XLII, PLATE II.
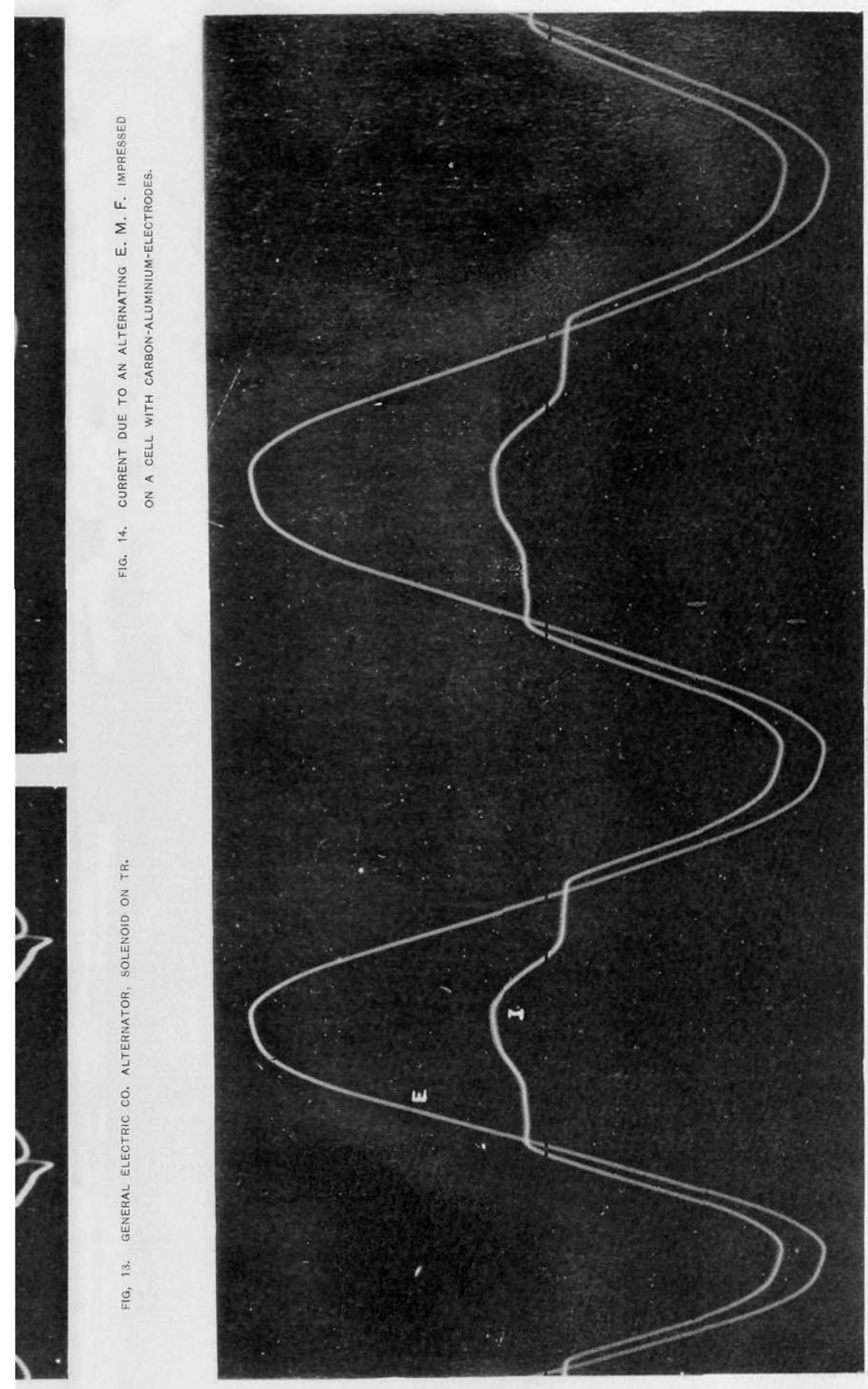

To face page $x 60$. 